\title{
Sustaining Tradition and Fulfilling Agreements on Traditional Medicine Since the Alma Ata Conference
}

\author{
Paschal Kum Awah, ${ }^{1,2 *}$ Dieudonne Nebane ${ }^{3}$ \\ ${ }^{1}$ Department of Anthropology, University of Yaounde, Cameroon \\ ${ }^{2}$ Centre for Population Studies and Health Promotion, Cameroon \\ ${ }^{3}$ HTTCKumba, University of Buea, South West Region of Cameroon, Cameroon
}

\begin{abstract}
Introduction: The implementation of traditional medicine strategies and their integration into the mainstream health systems by African governments has been a difficult process since its recommendation at the Alma Ata Conference of 1978.
\end{abstract}

Objective: This paper seeks to review how traditional medicine has survivedand what various African countries have done to implement traditional healthcare strategies and their integration into the national health systems as recommended by the Alma Alta conference of 1978.

Methodology: We purposively selected developed, middle income and African countries for the purpose of this review.We reviewed traditional medicine policies and programs in elevenpurposively selected countries from different political and economic blocks. We conducted a review of published works on traditional medicine implementation with more focus on the African continent. We have used the historical and thematic perspectives to obtain, organize and report data from published documents.

Results: There is the public use of traditional medicine in every African country at very high proportions. African governments celebrate African Traditional Medicine Days. But very few African countries have fully implemented Alma Ata recommended traditional medicine strategies and integrated traditional medicine into their national health systems to the latter. Strong adherence to tradition has kept traditional medicine in African alive. However, the coronavirus pandemic (COVID-19) has revealed strong adherence of Africans and their governments to African Traditional Medicine. But the developed world sticks to standard conventional medical practices. This reverence is an acknowledgment of the truism that rather than integrating African medicine into conventional medicine, proponents of African medicine would want to operate parallel to conventional medicine or integrate it into the African medical system.

Conclusion: African medicine exists in Africa as a culturally bound practice, therefore, providing solutions to health problems in situations where conventional medicine may not. It exists on its own without a real and strong legal framework to guide its practice because of its conflicting parallel validation methods to conventional medicine.

Keywords: African medicine, Traditional medicine, Implementation, Integration,Strategies, National health system, Alma ata

\section{Introduction}

Medicine has existed as part of human culture amongst all populations of theworld. All medicine started as being traditional to a given people until standard methods became available to test for toxicity, safety, and efficacy. Traditional medicine isone of the oldest, and perhaps the most assorted, of all therapeutic systems. ${ }^{1}$ The practice of medicine has been evolving differently according to peo ple's needs and technologies. Public health technology grounded countries have distinguished and named medicine differently. Someanthropologists have named western or conventional medicine as biomedicine and medicines of other cultures as ethno medicine. Biomedicine, though originating from Western culture, is universal. Any other medical practices besides biomedicine are considered
Quick Response Code:

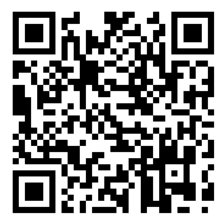

*Corresponding author: Paschal Kum Awah, Chair, Department of Anthropology, University of Yaounde I, PO Box 755, Yaounde, Cameroon

Received: 13 November, 2020

Published: 09 February, 2021

Citation: Paschal KA, Dieudonne N. Sustaining Tradition and Fulfilling Agreements on Traditional Medicine Since the Alma Ata Conference. Glob Res Archaeo Sci. 2021;1(1):1-16. DOI: 10.53902/GRAS.2021.01.000501 
ethnomedicine, otherwise known as traditional medicine. Africa and Asia are some of those continents with extensive and intensive practice of medicine grounded on their cultural practices. However, developed and middle income countries practice traditional medicine and call it complementary and alternative medicine or integrate it into mainstream conventional medicine. The most common traditional medicine in common practice across the African continent is the use of medicinal plants alongside divination. In many parts of Africa, medicinal plants are the most easily accessible health resource available to communities. ${ }^{1}$ Also, they are most often the preferred option for the patients. In Asia, meditation is deeply rooted in the medical systems inherent there.

This paper examines what some countries have done, so far, after the recommendations of Alma Ata, integrate Traditional Medicine (TM) into their health systems. It explainsthe extent to which some World Health Organization (WHO) member countries have implemented the recommendations of the Alma Ata Conference 42 years after. We also discuss what could be done for the WHO strategy on PHC to be fully implemented through integrating TM by all the countries. We will further our discussion into talking about the dynamics that have taken place in African traditional medicine especially with the coming of the new coronavirus of 2019 (COVID-19) which African populations claim that TM has started demonstrating its worth to cure, given that all trials with conventional medicine are delayed and have not produced the required results to meet the increasing need to safe life in developed countries.

\section{Methodology \\ probing into evidence}

The methodology for this paper is literature review of empirical research on traditional medicine. It is discussed in the subsections including time horizon ofreview, selection of journals, articles, countriesand article classification, andanalysis of articles.

\section{Time horizon}

We have chosen the review duration of over 40 years, starting from the year1978 to 2020 as the time horizon. The reason for selecting 1978 as the initiating year is because it is the year traditional medicine was a key theme of discussion on the global platform during the Alma Alta Conference introduced as a key concept of promoting primary health care (PHC). The end year (2020) is because traditional medicine surfaced on the global platform as a major alternative to tackle the coronavirus pandemic. Lots of debates about its tenability in Asia and African raised a lot of global health concerns.

\section{Selection of journals, articles and countries}

Several publications on African traditional medicine are available. We searched for articles related to Science Direct, Springer Link, Google Scholars, and Taylor \& Francis publication portals. Available references or reports in English and French on the use of traditional medicine were consulted from published scientific journals, books reports from national, regional, and international organizations. Literature was searched on international online data bases such as Pubmed, MEDLINE, Science Direct, Scopus, and Google using the MeSH words. For the search criteria, we used traditional medicine, African traditional medicine, and African traditional medicine integration. A similar methodology was used by Agbor and Naidoo ${ }^{2}$ and Flyn et al, ${ }^{3}$ when they conducted literature review on field different from traditional medicine. The choice of countries was purposeful, selecting countries that have some evidence of integration and implementation of traditional medicine. Further, the selection of countries followed a regional perspective. Three hundred articles were identified on traditional medicine. After review 50 of them were retained and exhaustively reviewed. The complete 50 lists of journals, books, and articles intraditional medicine are shown in the list of references. The list reveals that a majority of publications are from the World Health Organization. Therefore, we have further filtered out journals and articles. Thus the total number of reviewed articles came down to 178 published in 24 journals (the Appendix). The list of selected articles reviewed ison the references. These are the publications that are considered for thepresent review. The articles have a combination of conceptual, thematical, and empirical models. Many of them have focused on describing Field-based research, using data gathered from naturally occurring situations and on reports. In the present paper, we have considered articles from the three above models. Articles out of these three models were excluded.

\section{Analytical approach}

We conducted a review of the recommendations and suggestions made by WHO and other organizations and scholars on how traditional medicine should be treated by governments. We have purposively selected some African countries to see how the governments in those countries treat traditional medicine. We reviewed policy implementation in some African countries including Botswana, Cameroon, Cote d'Ivoire, Democratic Republic of Congo (DRC), Egypt, Ghana, Kenya, Madagascar, Nigeria, Senegal, and South Africa. The review has permitted us to obtain evidence from documents. There view path has taken us through WHO and individual authors' publications. The review style followed historical, ${ }^{4}$ thematic and diachronic perspectives. From the historical perspective, we traced the background of traditional medicine since its recommendation for use as was made at the Alma Ata Conference. In the thematic perspective, we compared emerging themes. We have discussed themes like native, primitive, civilized, ethnomedicine versus conventional, biomedicine, modern, uncivilized, integration, and implementation at the level of analysis. Through the diachronic perspective, we have analyzed the changes that have taken place over time in terms of the type of language used to describe traditional medicine.Grounded theory was used as the basis of analyses.

\section{Statistics, definitions, comparing traditional medical systems}

Emerging statistics: The World Health Organization (WHO) estimates that about $80 \%$ of the African population uses traditional medicine. ${ }^{5}$ Table 1 below is illustrative of the comparative trend between some selected industrialized and middle-income countries. ${ }^{6}$ 
Table 1: Trend of use of Traditional and Complementary Medicine in someselected industrialized and middle-income countries.

\begin{tabular}{|c|c|c|}
\hline Developed countries & \% & Year \\
\hline USA & 42 & 2003 \\
\hline Australia & 82 & 2013 \\
\hline France & 49 & 2003 \\
\hline Canada & 70 & 2008 \\
\hline Spain & 41 & 2012 \\
\hline Germany & 80 & 2008 \\
\hline $\begin{array}{c}\text { Middle income } \\
\text { countries }\end{array}$ & $\%$ & Year \\
\hline China & 80 & 2016 \\
\hline Columbia & 40 & 2003 \\
\hline India & 80 & 2008 \\
\hline Chile & 71 & 2003 \\
\hline Bolivia & 79 & 2015 \\
\hline Cuba & 99 & 2010 \\
\hline South Korea & 86 & 2013 \\
\hline Singapore & 76 & 2013 \\
\hline $\begin{array}{c}\text { Lao People's Demo- } \\
\text { cratic Republic }\end{array}$ & 80 & 2013 \\
\hline
\end{tabular}

Source: Table compiled by authors using statistics from the World Health Organization.

According to Table 1 above the use of traditional medicine in middle-income countries is higher than in developed countries. An equal proportion of Asian and Latin American populations use medicine grounded in their cultures. Where as many countries in Asia and Latin America have and are incorporating traditional medicine into their mainstream health system as recommended by WHO. African countries are yet to subscribe fully to this World Health Assembly Resolutions. ${ }^{7}$ This initiative of many governments, in these regions, is to incorporate traditional medicine practices to meet their primary health care needs. In industrialized countries, almost half the population now regularly uses some form of Traditional and Complementary Medicine (TCAM). Comparatively, the general use of traditionalmedicine by African countries is at least $80 \%$. However, Oyebode et al., ${ }^{8}$ have disputed these statistics arguing that theuse of traditional medicine is in decline after studying the use of traditional medicine in six populous middle-income countries. He revealed that the country with the greatest reported use of traditional medicine is India, where $11.7 \%$ of people reported that their most frequent source of care was traditional medicine, and $19.0 \%$ of people reported at least one consultation with a traditional medicine practitioner in the previous 12 months.

Evolving definitions: The definition of traditional medicine has evolved. Traditional medicine has been defined variously by different authors and organizations. The definition oftraditional medicine by the World Health Organization (WHO) has evolved. In 1978 $\mathrm{WHO}^{7}$ defined traditional medicine as the totality of the knowledge and practices, explicable or other wise for diagnosing, preventing, or eliminating any (human)disequilibrium, be it physical, mental, or social which is based exclusively, onthe experiences lived, observed, and transmitted from generation to generation either by mouth or through writing. Following on from this definition, Lantum ${ }^{9}$ held that traditional medicine is a blanket term covering all objects bethey solid, liquid, non-concoction, material, physical, and otherwise, which areproducts of nature capable of reforming human health or therapeutic utility with in a given cultural context. Furthermore, $\mathrm{WHO}^{5}$ defined traditional medicine as that which comprises diverse practices, approaches, knowledge, and sanitary beliefs including medicine based on plants, animals, and/orminerals, spiritual treatments, manual techniques, and exercises, applied onlyor in association to maintain wellbeing and treatment, diagnose or prevent illness. Following the definition of WHO, Shein and Maehira, ${ }^{10}$ defined traditional medicine as the total of the knowledge, skills, and practices basedon the theories, beliefs, and experiences indigenous to different cultures, whether explicable or not, used in the maintenance of health, as well as in the prevention, diagnosis, improvement or treatment of physical and mental illnesses. These definitions have been evolving and are culturally defined,therefore relative.

Looking across the boundaries of traditional medicine systems: There exist several traditional medicine systems in the global context. $\mathrm{WHO}^{5}$ talks of Chinese traditional medicine, Indian ayurvedic medicine, Arabic Unani medicine, and African traditional medicine. Diverse systems of indigenous alternative medicine have equally been developed over the centuries by Asiatic, African, Arabic, Amerindian, Oceanic, Central American, South American, and other cultures. Mbonji ${ }^{11}$ talks of Egyptian medicine, Babylonian medicine, Hebrew medicine, Amerindian medicine, Chinesemedicine, Arab-Moslem medicine, and even faith medicine practiced by prayerand faith groups. During the holding of the Alma Ata Conference in 1978, interest was given to traditional medicine because of its conspicuous use all over the world, and especially in Africa where it was revealed that about $80 \%$ of Africans use traditional medicine. The use of traditional medicine in the Africanregion was based on the fact that it was accessible, available, and affordable.

Given this context, traditional medicine emerged as one of the key issues discussed in the Alma Ata Conference in 1978 as one of the ways to strengthen the global strategy for primary health care. The Alma Ata Conference declaration (1978)came out with ten points of which points V and VII sub 7 stated respectively that governments have a responsibility for the health of their people which canbe fulfilled only by the provision of adequate health and social measures. Amain social target of governments, international organizations, and the global community in the coming decades should be the attainment by all peoples of the world by the year 2000 of a level of health that will permit them to lead asocially and economically productive life. In October 2018 at the Global Conference on Primary Health Care which was named The Declaration of Astana, it was adopted that the success of primary health care will be driven by applying scientific as well as traditional knowledge and extending access to arrange health care services, which include traditional medicines. ${ }^{12,13}$ Primary health care is the key to attaining this target 
as part of development in the spirit of social justice. Primary Health Care relies, at local and referral levels, on health workers, including physicians, nurses, midwives, auxiliaries, and community workers asapplicable, as well as traditional practitioners as needed, suitably trained socially and technically to work as a health team and to respond to the expressed health needs of the community. In the context of the coronavirus, primary health care is highly needed to enable communities across the globe to feel compelled to get tracked, tested, and treated. Traditional healers, likethose highly consulted for symptomatic infections, may be very instrumental in fulfilling these triple tasks.

\section{Integration, Dynamism, Implementation of Traditional Medicine in Health Systems}

Integrating Traditional Medicine into the Mainstream Health System: Following the recommendations of Alma Ata to integrate traditional medicine into the mainstream health systems, very few governments, especially in Africa have initiated some political and programmatic actions. The Essential Medicine and Health Product (EMHP) Department of WHO affirms that the Alma-Ata Declaration was significant for its recommendations on traditional medicine(TM). Although TM has been used for thousands of years and has made great contributions to human health, the Alma-Ata Declaration was the first recognition of the role of TM and its practitioners in primary health care by WHO and it's Member States. ${ }^{14}$

The conception, production, distribution, and use of TM have changed dramatically over the past forty years. Due to its affordability, availability, and accessibility, TM has played an important role in meeting the demands of primary health care in many developing countries, particularly in Africa and Asia. Since the 1990s, the use of traditional medicine has surged. ${ }^{5}$ It not only maintains its function in primary health care in developing countries(70-80\% of the population in India and Ethiopia still depend on TM andpractitioners for primary health care), but its use has expanded widely in many developed countries where it is referred to as Complementary or Alternative Medicine (CAM). For instance, $70 \%$ of the population in Canada and $80 \%$ in Germany have used TM as CAM treatment. ${ }^{14}$ In the $21^{\text {st }}$ century, national health authorities were asked to consider how to integrate TM/CAM into their national health systems. This dynamism in policy has given more impetus to traditional medicine. ${ }^{14}$ It has taken much time for traditional medicine to get to the level at which it is today since the holding of the Alma Ata Conference on health in 1978. Within this period of at least 40 years, much was supposed to have been done by thevarious WHO countries in Africa on the implementation of its recommendation. However, other subsequent conferences and seminars have been organized after Alma Ata to reinforce its recommendations or propose other strategies of solving the numerous health problems that the continent has been facing using traditional medicine. This is seen in the example of the Global Conference on Primary Health Care which was held in Astana, Kazakhstan from 25-26 October 2018 and came out with the Astana Declaration, a follow up of the Alma Ata Conference of 1978.

\section{Historical overview of the development of traditional medicine in Africa}

For a long time, human beings through observation and practical experiences learned to use different plant species that led to the emergence of traditional medicine (TM) systems. ${ }^{15}$ The ancient Pharaonic Egyptian TM system is one of the oldest documented forms of TM practice in Africa and the pioneer of the world's medical science. ${ }^{15}$ However, the medical practices diffused very fast to other continents being accelerated by the advancement of technologies while leaving Africa lagging in the integration of the practice in the formal health-care system. ${ }^{15}$ Traditional medicine in Africa has gone through several stages since its existence. Fontaine ${ }^{16}$ distinguished three historical periods in the development of traditional medicine. They correspond to different political and economic situations. In the African continent these historical periods include the pre-colonial period, the colonial period, and the post-colonial period. Fontaine ${ }^{16}$ holds that the pre-colonial period was when healers, fetishists, and traditional midwives practiced their art freely and were in any case sole guardians of the people'shealth. Traditional medicine was the only medicine known to the people duringthis period. The people used traditional medicine and consulted traditional healers. There was confidence in traditional medicine and traditional healers.

Mbonji ${ }^{11}$ concludes that Africans did not wait for the arrival of Nivaquineto treat their diseases else, they would have disappeared from the surface ofthe earth before now. This is an indication that there was traditional medicine which the people used to handle their health problems. The next stage described by Fontaine ${ }^{16}$ was the colonial period which brought in colonial powers' civilization, religion, medicine, and technology aimed at looking after the interest of the colonialists in the urban centers or areas with colonialists enterprises based on agricultural or mining potential. This is what became known as modern medicine. During this period, traditionalmedicine was repressed; its practitioners and users made sure that suchactivities went on without the knowledge of the colonial authorities. Mbonji ${ }^{11}$ writes about the case of Cameroon that traditional medicine waspursued because it was perceived as witchcraft and some disorderly superstitions. It was banned and made an offense in the law if anyone was caught practicing it. Mbonji ${ }^{11}$ still discusses the decree signed by the then French President on $19^{\text {th }}$ November 1947 into the penal code applied in Cameroon and all territories under French control incriminating the practice of witchcraft, magic, hand charlatanism. Much other legislation was put in place to obstruct the practice of traditional medicine in Cameroon like in many other African countries. It is because of colonialism that African medicine was thendescribed as "native", "ethnomedicine", "primitive", "uncivilized", "alternative"as opposed to Western medicine which has names as "conventional","biomedicine", "modern medicine", "mainstream", "orthodox" etc. The above terms have been used by people and authors depending on their views.Fontain $\mathrm{e}^{16}$ goes ahead to describe the third stage known as the postcolonial period. This was the era of independence in which traditional medicine recovered its former status in many countries 
in an attempt to bring about recognition, official status, harmonization, and collaboration. In Cameroon for instance, there was an urgent need to safeguard the therapeutic heritage of traditional medicine. There was the creation of traditional medicine associations, traditional medical practice come to the open, recommendations were made to governments as a way of improving primary health care to integrate traditional medicine into their National Health Systems. ${ }^{9}$ This was one of the significant outcomes of the 1978 Alma Ata Conference organized by WHO. Hence, the post-colonial period gave importance to traditional medicine again after it had gone underground due to colonial denial and repression.

In addition to the historical overview mentioned above, many other authors have rated traditional medicine differently. Good ${ }^{17}$ explains that the earliest anthropological writings on culture and medicine share much of the embarrassing evolutionary language of other parts of the field. Conventional histories of Medical Anthropology outline a heritage that includes the writings of W.H.R. Rivers, Forrest Clements, historian Erwin Ackerknecht, and others forwhom terms like "primitive", "magical", "pre-colonial", "proto-scientific", and"folk" are all, common adjectives for "medical beliefs" among "natives". These ideas that have dominated the conception of traditional medicineby the western world were all biased. Until the beginning of the $19^{\text {th }}$ Century, all medical practices were based on what we now call traditional medicine. The new way of looking at things subjected all assumptions to experiment and statistical validation and foresaw the future in terms of research andorganization. Of necessity, it introduced doubt where previ- ously there had been belief. It emphasized intellect and logic and be littled emotion and intuition. $\mathrm{WHO}^{5}$ holds that at present, about half the world's population resides incountries where ministries or government departments are responsible for traditional medicine, and in many countries, $80 \%$ or more of the population living in rural areas are cared for by traditional practitioners. The relationship between conventional and traditional health care practitioners is, therefore, one of the major concerns, although in some countries health administrators will not admit the existence of any such problems. Traditional medical practitioners, many of whom have suffered from official neglect or even persecution, have expressed grave doubts about this relationship. Confident of their power and skills, and unimpressed by the quality and coverage of the official health services, they are confronted by many problems.

\section{Levels of implementation of the recommendations of the Alma Ata Conference}

The WHO Conference that was held in Alma Ata in 1978 discussed global health issues and Primary Health Care (PHC). It recognized the worth of traditional medicine because it showed that about $80 \%$ of Africans relied on and used traditional medicine. Hence, they recommended African governments integrate traditional medicine into their PHC programs. From then onwards, severaldiscussions have taken place on how traditional medicine could be handled by African governments in realizing its health needs. The following Table 2 summarizes the level of engagement of some African countries in integrating traditional medicine in their health systems.

Table 2: Level of integration of Traditional Medicine in some African countries' national health systems.

\begin{tabular}{|c|c|c|c|c|}
\hline Country & $\begin{array}{c}\text { Public use of TM by the } \\
\text { community and individ- } \\
\text { uals }\end{array}$ & $\begin{array}{c}\text { Celebration of African TM } \\
\text { Day by governments }\end{array}$ & $\begin{array}{c}\text { Total Integration of TM } \\
\text { into the NHS }\end{array}$ & $\begin{array}{c}\text { Existence of a legal frame- } \\
\text { work on TM in the NHS }\end{array}$ \\
\hline Botswana & Yes & Yes & No & No \\
\hline Cameroon & Yes & Yes & No \\
\hline Cote d'Ivoire & Yes & Yes & No & No \\
\hline DRC & Yes & Yes & No & Yes \\
\hline Egypt & Yes & Yes & No & No \\
\hline Ghana & Yes & Yes & Yes \\
\hline Kenya & Yes & Yes & Yes & No \\
\hline Madagascar & Yes & Yes & No & Yes \\
\hline Nigeria & Yes & Yes & No & No \\
\hline Senegal & Yes & Yes & Yes & \\
\hline South Africa & & & Nes & No \\
\hline
\end{tabular}

Source: The authors' compilation from reviewed publications.

Table 2 above summarizes the situation of traditional medicine integration in some African countries. It shows that most countries have recognized the existence and the worth of traditional medicine in their various countries. However, there is a reluctance in making traditional medicine a part of the national health system. Tsekpo $^{18}$ explains that at the Alma Ata Declaration of 1978, it was resolved that traditional medicine had to be incorporated into the health care systems in developing countries if the objective of the
"Health for All by the Year 2000" was to be realized. Notwithstanding this strategy, African countries did not come near the objective at the end of the $20^{\text {th }}$ century. Therefore, the Member States of the WHO African Region adopted a resolution in 2000 called" Promoting the role of traditional medicine in health care systems: A strategy for the African Region". This strategy provided for the institutionalization of traditional medicine in the health care systems of the member states of the WHO African Region. Furthermore, the 
OAU (now called African Union) Heads of State and Government declared the period 2000-2010 as the African Decade on African Traditional Medicine. The Director-General of the World Health Organization declared $31^{\text {st }}$ August every year as African Traditional Medicine Day, in which he said it is in cumbent on governments in the Region to reverse the erosion of the centuries-old traditional medical knowledge and practice. ${ }^{6}$ This way, they will be restoring the glory of traditional medicine to its pride of place, and perpetuating the culture of its utilization. ${ }^{6}$ All these declarations signify the importance and the approval by governments and international institutions of the need to institutionalize African traditional medicine in health care.

Therefore the mechanisms for institutionalization have to be developed to make these resolutions a reality. Given the complexity and heterogeneity of African traditional medicine, a system of incorporation in the current healthcare systems has to be developed.
Tsekpo $^{18}$ highlights some of the relevant guidelines developed by the WHO Regional Director for Africa that the Member States can adopt or adapt as may be appropriate. These guidelines have to do with: the formulation, implementation, monitoring, and evaluation of a National Traditional Medicine Policy; a model legal framework for the practice of traditional medicine: the Traditional Health Practitioners Bill; a model Codes of Ethics for Traditional Health Practitioners; a regional framework for the registration of traditional medicines in the WHO African Region; and a regulatory framework for the protection of intellectual property rights (IPR) and indigenous knowledge of traditional medicines in the WHO African Region. These guidelines and others provide a basis for the incorporation of African traditional medicine in a manner that would best suit a particular country. The WHO Regional Director for Africa also appointed a Regional Expert Committee on Traditional Medicine which assists in the development of these guidelines. The following Table 3 shows the level of implementation of the above guidelines.

Table 3: The level of implementation of the above guidelines Country.

\begin{tabular}{|c|c|c|c|c|c|c|c|}
\hline \multirow[t]{2}{*}{ Country } & \multicolumn{7}{|c|}{ Level of implement of guideline } \\
\hline & $\begin{array}{l}\text { Doctor-Patient } \\
\text { ratio }\end{array}$ & $\begin{array}{l}\text { Ratio of Tradi- } \\
\text { tional healers } \\
\text { to the total } \\
\text { population }\end{array}$ & $\begin{array}{l}\text { Guidelines for } \\
\text { the formula- } \\
\text { tion, imple- } \\
\text { mentation, } \\
\text { monitoring and } \\
\text { evaluation of a } \\
\text { National Tradi- } \\
\text { tional Medicine } \\
\text { Policy }\end{array}$ & $\begin{array}{l}\text { Model legal } \\
\text { framework for } \\
\text { the practice } \\
\text { of traditional } \\
\text { medicine: the } \\
\text { Traditional } \\
\text { Health Practi- } \\
\text { tioners Bill }\end{array}$ & $\begin{array}{l}\text { Model Codes of } \\
\text { Ethics for Tra- } \\
\text { ditional Health } \\
\text { Practitioners }\end{array}$ & $\begin{array}{l}\text { Regional } \\
\text { framework for } \\
\text { the registration } \\
\text { of traditional } \\
\text { medicines in } \\
\text { the WHO Afri- } \\
\text { can Region }\end{array}$ & $\begin{array}{l}\text { A regulatory } \\
\text { framework for } \\
\text { the protection } \\
\text { of intellectual } \\
\text { property rights }\end{array}$ \\
\hline Cameroon & $1.1: 10000$ & 0.180555556 & Yes & No & No & Yes & Yes \\
\hline Botswana & 23.8:100,000 & No data & Yes & No & No & Yes & No \\
\hline Cote d'Ivoire & $1: 9,739$ & No data & Yes & No & No & Yes & No \\
\hline DRC & $6.9: 100,000$ & No data & Yes & No & No & Yes & No \\
\hline Egypt & No data & No data & Yes & No & No & Yes & No \\
\hline Ghana & $6.2: 100,000$ & 0.180555556 & Yes & No & No & Yes & Yes \\
\hline Kenya & $13.2: 100,000$ & 0.701388889 & Yes & No & No & Yes & No \\
\hline Madagascar & No data & No data & Yes & Yes & No & Yes & No \\
\hline Nigeria & $18.5: 100,000$ & 0.118055556 & Yes & No & No & Yes & No \\
\hline Senegal & $7.5: 100,000$ & No data & Yes & No & No & Yes & Yes \\
\hline South Africa & 0.736111111 & 0.527777778 & Yes & No & No & Yes & Yes \\
\hline
\end{tabular}

Source: The authors and WHO statistics.

The following country case-by-case analyses provide details of the summaries in Tables 2 and 3. In this country review, we shall discover that Ghana and Madagascar have legalized their traditional medicine making them be at an advanced level more than the other countries in our sample.

Botswana: $\mathrm{WHO}^{19}$ in Essential Medicines and Health publishes that the first reference to the official acceptance of traditional medicine practitioners in Botswana appears in Section 14.86 of the National Development Plan of 1976-1981. Although not part of the modern health care system, the traditional healer (ngaka) performs a significant role in Botswana, especially in the rural areas. The policy of the Ministry is to evaluate further the contribution of tradi- tional healers to the health care system of the country and possibly then to seek ways of closer cooperation and consultation. There are a large number of traditional practitioners of various types who are frequently consulted on health and personal matters. The Ministry of Health will continue its policy of gradually strengthening links with traditional practitioners - diviners, herbalists, and faith healers. The emphasis will be put on improving mutual understanding, especially about the practices and techniques of the traditional practitioners. No full-scale integration is envisaged, but referrals between modern health care services and traditional practitioners will be encouraged where appropriate. Despite the efforts mentioned above, Geiselhart21 writes that traditional medicine has not been integrated into the national health system of Botswana. We 
observed that Botswana does not have a law enacted in parliament for the practice of traditional medicine. This situation makes it difficult for the smooth implementation of the 1978 Alma Ata declaration which asked WHO member countries to integrate traditional medicine into their national health systems to realize primary health care.

Cameroon: The government of Cameroon has put in place some of the recommendations of the WHO since the Alma Ata conference of 1978. However, Hillenbrand ${ }^{22}$ concludes that incorporating traditional medicine into mainstream medicine in Cameroon is not a priority for the government and this situation has created mistrust between the practitioners of conventional medicine and those of traditional medicine. Fokunang ${ }^{23}$ indicates that to integrate TM into the national healthcare system of Cameroon the WHO in collaboration with the Cameroon Government has put in place a strategic route map for TM integration by 2012 . In essence, this plan has not been realized as expected. Lantum and Monono ${ }^{24}$ make a brief catalog of some of the things that the government of Cameroon has done in the implementation of WHO strategies for traditional medicine in Africa. The government of Cameroon had encouraged the census of traditional healers, authorization for the setting up of Chinese medicine hospitals, the creation of service of traditional medicine in the ministry of health in 1995, acknowledging that traditional medicine could be used in the fight against HIV/AIDS epidemic, the official implementation of Traditional Medicine Days every $31^{\text {st }}$ August, the setting up of a unit of traditional medicine at the Yaounde Central Hospital in 1981, then putting in place a law in 1990 on the freedom of associations which favored the creation of traditional medicine associations all over the country. Apart from these, Mbonji ${ }^{11}$ also brings out in historical form the conventions and legislations on traditional medicine in Cameroon. After castigating traditional medicine during the colonial period, it came out stronger again during the postcolonial period with many traditional medicine associations for instance. Fokunang ${ }^{23}$ writes that the WHO and the Government of Cameroon have signed a convention to draw up a strategic plan for the valorization of TM in Cameroon. However, despite this program in progress as he mentions, it has faced many difficulties which have been blamed on the following: The lack of institutional support for production and dissemination of key species for cultivation; The low prices paid for traditional medicinal plants by herbal medicine traders and urban herbalists; Lack of appropriate technology for post-harvest and pre-processing purposes adapted productively and effectively; Insufficient documentation and scientific experimentation for verification of the herbalist's claims; Lack of preservation of medicinal extracts for extended shelf life. As Lantum and Monono ${ }^{24}$ put it, there is the political will to put in place legislation to officially recognize traditional medicine as well as lay guidance for its operation. Fokunang ${ }^{23}$ quoting; indicates that in the past few years, Cameroon joined most of the developing countries in recognizing that they do not have the means to provide comprehensive health care like some industrialized countries, and have started taking more interest in promoting the use of traditional remedies. Yet, as Fokunang ${ }^{23}$ quoting traditional healers are not accepted but tolerated because of the decree that has created a harmonization of the primary health care involving all stakeholders. No laws are guiding the TM practice in Cameroon. The TM sector is volatile and isolated and uncensored, and anyone can enter the trade and this has consequently led to breeding quacks or what is known as "charlatans". There are also competitions in the trade between medics and traditional healers for patients, "thus the saying goes that the winner takes it all". The party with provisions of the best incentive gets the patients. Lack of proper integration of traditional medicine in health care systems. Traditional healers are not attached to bodies like malariaor HIV/ AIDS control committees is an issue. They are not involved in the running of services in charge of their work in the ministry of health, they are not attached to top research centers, and are rarely allowed to consult in health care institutions as in other countries in Africa.

Despite the things listed in the WHO report on traditional medicine, ${ }^{12}$ we conclude that traditional medicine in Cameroon still has a long way to go for it to be completely integrated into the mainstream of health care. The coming of the corona virus has further supported this view. Ekonde ${ }^{25}$ writes that the Arch Bishop of Douala who has been into traditional medicine research since 30years ago announced a herbal cure for Covid-19 in April 2020 and named it Elixir COVID in June 2020. The herbal cure is still undergoing investigation by the Cameroon government through the Ministry of Health (MOH). However, he announced in July that he had used it to cure about 1500 patients saying that people with respiratory problems start breathing normally after 24 hours. Ekonde ${ }^{25}$ concludes that Cameroon's parliament has acknowledged the use of traditional medicine to roll back Covid-19 and urges the government to invest in research into potential treatments. The Cameroon parliament through its president in June 2020 urged Cameroonians from stigmatizing and marginalizing traditional medicine but recommended collaboration and complementarity between traditional medicine and conventional medicine. On the $31^{\text {st }}$ of August 2020, the Minister of Public Health announced on the occasion of the celebration of the African Traditional Medicine Day that there isa law on traditional medicine that is being elaborated that will eventually be tabled to the parliament for voting. This is an indication that Cameroon still falls short of the expectations of this paper.

Cote d'Ivoire: Cote d'Ivoire has neither official legislative nor regulatory texts governing traditional medicine. There is no licensing process for traditional health practitioners, nor are there procedures for the official approval of traditional practices or remedies. Traditional medicine practitioners are not involved with primary health care in Cote d'Ivoire on either the local or national level. ${ }^{20}$ However, according to Kabupwe, ${ }^{26}$ the Ivorian President signed adecree No 2016-24 of 27 January 216 relating to the Code of Ethics for Traditional Medicine and Pharmacopoeia practitioners. This text establishing the code of ethics applies firstly to traditional medicine and pharmacopeia practitioners authorized to practice their art in Ivory Coast and to their employees who have completed an internship of at least six months in the fields above. This Decree also sets several general duties and scope off or the traditional medicine practitioner. In this context, the practitioner of traditional 
medicine must exercise his art with respect for life and the human person. He must also practice his art with honor and dignity. He must personally perform all the necessary acts for the efficient management of his customers. In addition to the general duties, practitioners owe each other support and assistance in the exercise of their art. They must show loyalty and solidarity with each other. They are prohibited as such to encourage employees to break their work contract. The Decree also provides for certain duties and prohibitions for health professionals and obligations towards the sick.

Regarding the management and the ethical use of traditional medicines, the Decree states that the practitioner must refrain from destroying medicinal plant species. He is expected to use, in the exercise of his art, natural plant, animal, or mineral substances that should be neither mixed nor combined with known pharmaceutical products during preparation or manufacturing. According to this Decree, any establishment that sells and provides sick people with poor quality, outdated, denatured, or mislabeled traditional medicines shall be closed. This decree shows that the implementation of traditional medicine policy in Cote d'Ivoire is evolving. There is a strong government will to enhance the status of traditional medicine. $\mathrm{WHO}^{12}$ reports that $\mathrm{T} \& \mathrm{CM}$ providers practice in private clinics, health care centers, and herbal stores. The Government officially recognizes training programs, such as an apprenticeship with a T\&CM provider (without the certificate or licensing); it also recognizes programs, such as training in conventional hygiene, anatomy, sustainable use and conservation of medicinal plants, and data collection and management. ${ }^{12}$ However, despite this evolution, the status of traditional medicine in Cote d'Ivoire has still not met the recommendation of the 1978 Alma Alta Conference which obliged most importantly that traditional medicine is integrated into the National Health Systems of WHO member countries so that it would help in solving issues of primary health care.

Democratic Republic of Congo (DRC): $\mathrm{WHO}^{19}$ published that Congo has official legislation and regulatory instruments governing the practice of traditional medicine. It also has local and national intersect oral councils for traditional medicine. Local officials in Congo are allowed to authorize the practice of traditional medicine in their administrative and/or health subdivisions. Some traditional medicine practitioners are also involved in the primary health care program of Congo. However, in certain centers, this integration is very weak. There is a licensing process, a national association, and a registry of traditional health practitioners. The Management of Health Services of the Ministry of Health, the National Union of Trade-Therapists, and other professional traditional medicine associations review the qualifications of traditional medicine practitioners, although there are no set criteria for these qualifications. $\mathrm{WHO}^{19}$ continues that traditional medicine practitioners are recognized by the Government and are well tolerated. In 1996, legislation on the recognition of traditional medicine and complementary/ alternative medicine was drafted, but it has not yet been finalized because of the 1997-1999 armed conflict. Under current regulations, only herbalists are permitted to practice in the official health care system. This is clear proof that African medicine in the DRC has advanced publicly, yet it lacks that legal instrument to back it up which this paper is interested in. Traditional healers especially herbalists are involved in the production of many herbal drugs. However, its total integration into the national health system still has some conditions to fulfill. Memvanga et al, ${ }^{27}$ concludes that to ensure the integration of a larger number of plant-derived products in the Congolese healthcare system, some parameters and trends should be considered in further researches, in agreement with the objectives of the "Traditional Medicine Strategy" proposed by the World Health Organization in 2013. ${ }^{28}$ Although traditional healers are well used in the DRC like in the case of Diabetes Mellitus, they lack a law to protect their activities which could pave the way to fulfill the recommendations of Alma Ata.

Egypt: It is known that civilization started in Egypt. This includes all aspects of development. Brazier ${ }^{29}$ opines that the ancient Egyptians had sophisticated methods of practicing medicine that combined the supernatural with the natural, such as herbal remedies and surgery. Nahla et $\mathrm{al}^{30}$ discuss the economic value of medicinal plants in Egypt and includes that now a days, there is an increasing trend towards the use of herbal medicine in Egypt that reflects increasing confidence in such remedies. Recently, the production of herbal drugs and herbal drug-based medicaments is a growing industry in Egypt. Nahla et $\mathrm{al}^{30}$ adds that about 300 drugs, mainly imported, can be found in the Egyptian market today. Besides, Egypt has one of the largest biodiversity and is a country with agricultural traditions. The flora of Egypt includes about 2000 species of plants distributed in its different localities that vary in type of soil and prevailing climatic and other environmental conditions that hence encourage the growth of a wide range of plant species. Nahla et al30 quoting ${ }^{31}$ says that also, many plants have been successfully introduced and acclimatized in Egypt. Egypt is characterized by an abundant production of medicinal and aromatic plants that are exported all over the world and is considered as one of the most important sectors that can be relied upon to increase the volume of Egyptian exports due to the growing global demand..$^{30}$ Of the African countries, Egypt is by far the largest exporter in terms of both volume and value. Egypt's 2008 exports of selected botanicals amounted to $77,850,312 \mathrm{~kg}$ with a reported value of USD $174,227,384$. Nahla et $\mathrm{al}^{30}$ then conclude by saying that the top five destinations for Egyptian medicinal plants in terms of reported value were the USA (26.2\%), Germany (24.9\%), Poland (4.3\%), Netherlands (3.9\%), and Russian Federation (3.7\%). The top five destinations for Egyptian herbal extracts and saps in terms of reported value were Saudi Arabia (29.4\%), United Arab Emirates (7.8\%), Syria (7.1\%), Yemen (6.3\%), and Algeria (5.8\%). The practice of traditional medicine in Egypt is limited to very few traditional medical providers. However, those who practice biomedicine in Egypt in corporate aspects of supernatural and natural healing. There is now established legislation on the practice of traditional medicine in Egypt. Traditional medicine is an integral part of Egyptian culture like modern medicine that is believed to have emerged and evolved from there. It is considered as an already legitimate practice that does not need special legislation. Therefore, the Egyptians do not find it obligatory to establish legislation on an aspect of their culture that enables them to seek solutions to health problems. For that reason, traditional medicine and biomedicine are practiced in an integrated manner. 
Ghana: As in most African countries, traditional herbal medicine is important in the health care delivery system in Ghana. Ghana has made much effort to meet there commendations of Alma Ata. Traditional medical practice in Ghana still operates in the informal economy, hence, there is the challenge is to elaborate a regulatory framework for the practice of traditional medicine while creating space for the informal practitioner to gainfully operate. WHO19 writes that the Traditional Medicine Unit under Ghana's Ministry of Health was created in 1991. In 1999, this was upgraded to the status of a directorate. The Ministry, in collaboration with the Ghana Federation of Traditional Medicine Practitioners' Associations and other stakeholders, has developed a five-year strategic plan for traditional medicine, which outlines activities to be carried out from 2000 to 2004. It proposes, among other things, the development of a comprehensive training program in traditional medicine from basic to tertiary levels. Efforts are being made to integrate traditional medicine into the official public health system. In the $\mathrm{WHO}^{19}$ publication, it was expected that by the year 2004, certified efficacious herbal medicines will be prescribed and dispensed in hospitals and pharmacies.

Since then, the Ghanaian government has made much effort to upgrade traditional medicine in Ghana. In Ghana, there is a national policy on Traditional and Complementary Medicine (T\&CM), titled Policy of Traditional Medicine Development in Ghana, which is also integrated into the Policy on Protection of Genetic Resources. ${ }^{13}$ Herbal medicines are regulated partly in the same way as conventional pharmaceuticals, in the category of herbal medicines. ${ }^{13}$ Herbal medicines are sold with medical, health, and nutrient content claims that are regulated by laws, but those laws are weakly enforced.$^{13}$ Local officials are allowed to authorize the practice of traditional medicine in their administrative and/or health subdivisions. ${ }^{19}$ In Ghana, the government reimburses patients' consultations with traditional health practitioners through an insurance scheme and is planning to do the same for the herbal medicines in its national essential medicines list. ${ }^{13}$ The Government of Ghana has set aside the third week of March every year as Traditional Medicine Week, starting from the year 2000. It is expected in this paper that despite this development in the implementations of Alma-Ata, ${ }^{7}$ more still needs to be done so that traditional medicine in Ghana is considered an integral part of the national health system operating on a parallel basis with conventional medicine.

Kenya: Kenya has made some efforts in responding to the recommendations of Alma Alta. Harrington ${ }^{31}$ writes that, since the World Health Organization's Alma Ata Declaration of 1978, which delivered international recognition for the role that traditional medicine and its practitioners can play in primary health care, the attitude has been softening. In 1984, a Traditional Medicines and Drugs Research Centre was established as part of the Kenya Medical Research Institute. More recently, supporters of the sector have looked east, to China, drawing inspiration from a model that has been able to integrate traditional medicine into the formal health care system whilst creating a sizeable and profitable export industry. ${ }^{31}$ Yet Kenya has failed to take practical steps to emulate China and has fallen behind African countries like Ghana that have led the way in efforts to integrate traditional healthcare into the biomedical system. Harrington ${ }^{31}$ continues that although the great bulk of state health care resources are allocated to the delivery of biomedical care, in rural areas traditional healers are the most accessible health care provider. The doctor-patient ratio in Kenya is approximately 1:33,000; for traditional healers, the ratio is $1: 950$.

Madagascar: Traditional medicine in Madagascar is officially recognized since 2007 as alegitimate practice. Pierlovisi and Pourche $\mathrm{z}^{32}$ write that traditional medicine in Madagascar was legalized by a ministerial decree in 2007 as biomedicine which allows healers if they performed the necessary steps to practice their art freely. Hence, the government of Madagascar wishes through this legalization to promote traditional medicine improves health care coverage, and enhances collaboration with modern medicines. Pierlovisi and Pourchez ${ }^{32}$ continue that the legalization was followed by the creation of the Pharmacopoeia and Traditional Medicine Service (PTMS) within the public health ministry. It is working on the integration of traditional medicine in the health care system, and it collaborates with the National Association of Tradi practitioners of Madagascar (NATM) which is responsible for doing the inventory and recruitment of the totality of the healers practicing all over Madagascar from urban areas to remote villages. The PTMS estimates that there are about 60,000 tradi practitioners in Madagascar with about 2000 registered through some local association given that they cannot register individually.

We consider that Madagascar has advanced with the process of the recognition of traditional medicine, its use, and collaboration with conventional medicine, especially when it is compared with other countries discussed in this paper. Despite the advanced status of traditional medicine in this country, Pierlovisi and Porchez ${ }^{32}$ discuss that there are some difficulties. They say that there is no strict legislation on intellectual property rights, there are also mixed feelings expressed by both the tradit practitioners and the conventional medical doctors on collaboration and access to health care remains difficult in certain remote areas, as well as other issues. But Pierlovisi and Porchez ${ }^{32}$ conclude that the exceptional biodiversity in Madagascar and the presence of the Ombiasy, the local healer, allows traditional medicine to continue.

The efforts being made by the government of Madagascar to promote the existence and use of traditional medicine are encouraging especially to traditional healers and users. This can be seen in the efforts of its current president who has come out to the media to announce and promote a traditional medicine herb COVID-Organics which treats corona virus (COVID-19). Many other African countries have imported this medication in their various countries to use in the treatment of the corona virus, though the WHO thinks that it still needs to undergo some clinical trials before its recognition. Hence, the WHO and some other African countries are currently testing the herbal remedy and other therapies. This is a serious call for Africans to rethink the future of their medicine which has been relegated up till now because of Western viewpoints.

Nigeria: Nigeria has gone a long way towards the legalization of traditional medicine in that country. Ekeanyanwu ${ }^{33}$ writes that in 
Nigeria, traditional medicine practices are the main source of livelihood for a significant number of populations who depend on it as their main source of income. High population growth rate $(2.8 \%$ annually) and poverty coupled with dwindling economic reserves in the country make Nigerians resort to more affordable sources for their immediate health needs. As the population increases, demand for traditional medicine will increase to provide affordable health care services especially, to those who cannot afford biomedicine. Several state governments have created Traditional Medicine Boards through which the states have tried to institutionalize the use of traditional medicine.

Nigeria has established national and state traditional medicine boards for the regulation of herbal medicine practice and to promote cooperation and research. ${ }^{33}$ The Federal government has also set up and financed the Federal College of Complementary and Alternative Medicine, Lagos, under the Federal Ministry of Health to train herbalists on its use and practices. Herbalists are also being encouraged to register their proven and efficacious standardized herbal preparations with the National Agency for Food and Drug Administration and Control (NAFDAC). Consequently, a center for research in traditional complementary and alternative medicine established in June 2017 aims to support the World Health Organization program in integrating traditional medical practice into public healthcare in Nigeria and around the globe. The center is to support the work of the WHO Traditional Medicine Strategy 2014-2023, assist the Federal, state, and local governments in Nigeria develop policies and implement plans that strengthen the role traditional medicine (TM) plays in keeping populations healthy. The center will work in collaboration with the Nigerian Council of Physician of Natural Medicine (NCPNM) and other traditional medical practitioners. The Nigerian government through its minister of health during the celebration of the African Traditional medicine Day in 2018 encouraged collaboration between the Federal Ministry of Health and the National Agency for Food Drug Administration and Control (NAFDAC), for the registration of medicines produced in Nigeria and maintaining a record of the drugs. However, these efforts demonstrated above have not yet resulted in the legalization of traditional medicine in Nigeria which is the culmination of the integration of traditional medicine into the national health system.

Senegal: Senegal has implemented the recommendations of Alma Ata to a very large extent. In Senegal, Iwasa and Ohno34 write that some facilities for traditional medicine are equipped with Western-style medical devices, and patients were allowed to choose a treatment method (Western medicine or traditional medicine) based on their test results. Also, Western physicians introduced traditional medicine to patients, and traditional healers introduced Western medicine to patients, showing that a blend of healthcare with special features of each form of medicine, instead of vertically segmented medical care, is provided in Senegal. In Senegal, approximately $60 \%$ of the citizens prefer Western medicine to traditional medicine, and $30 \%$ favor both, ${ }^{34}$ suggesting that for these citizens, Western and traditional medicine cannot be separated. Therefore, beyond personal preference between Western and traditional medicine, but it is more a question of which option is safer and more reassuring to citizens. Offering medical care with physical, mental, and spiritual fulfillment requires that traditional healers understand Western medicine and the physicians and for Western physicians to understand traditional medicine and the healers. ${ }^{34}$

As published by the $\mathrm{WHO}^{12}$ traditional medicine was officially recognized by the Government of Senegal in 1985. Senegal has a registry of traditional health practitioners. The Health Ministry advocates the promotion and rehabilitation of traditional medicine and traditional pharmacopeia. There are official strategies and activities to encourage collaboration between traditional and allopathic medical practitioners. This is justified with the efforts of Dr. Erick Gbodossou as reported by Bobb ${ }^{35}$ for Voice of America (VOA) has worked with traditional healers for 30years and founded PROMETRA, an association that promotes understanding of traditional medicine. Dr. Gbodossou explains that "Conventional medicine just works on the physical body. But traditional medicine works in the holistic approach," "This is very different, very important. Because the human being is not just an organ, mechanical, no; the human being is all." Dr. Gbodossou's Center for Traditional Medicine in Fatiq promotes collaboration between the two kinds of treatment. The Center Director, Charles Katy-Diop says the sick are diagnosed with modern equipment but their treatment is by traditional methods. The CentreDirector goes further to add that: "The medical doctor is here only for examinations, for blood analysis and so on. But he is not allowed to give treatment because it is a traditional (healing) center". Haque ${ }^{36}$ of Aljazeera Television writes that the government of Senegal has made efforts to legalize traditional medicine but has faced resistance from biomedical practitioners who think that this act will be to legalize witchcraft. In Senegal, the national policy for T\&CM is integrated into the Strategic Plan for Promotion of Traditional Medicine in the Health Care System. ${ }^{12}$ The national regulation on herbal medicines is the same as that for conventional pharmaceuticals: "Law 65-33 modifying the provisions of the public health code on manufacturing, sale, and advertisement of pharmaceutical specialties. ${ }^{12} \mathrm{~T} \& \mathrm{CM}$ providers practice in the private and public sectors (WHO,2019). The regulatory requirements for the safety assessment of herbal medicines are the same as that for conventional pharmaceuticals and herbal medicines are sold in pharmacies and other outlets as non-prescription medicines, self-medication, and by traditional practitioners. ${ }^{12}$ As such, we can observe that traditional medicine is officially used in Senegal and it is backed by laws that are an indication that Senegal has progressed to an advanced level as compared to other countries in Africa.

South Africa: In the South African experience, there have been improvements in the legal and policy framework of South Africa based on the WHO guidelines. However, there are currently no guidelines or framework for the registration of TM in South Africa. ${ }^{37}$ There is no national regulation of herbal medicines; however, under draft regulations, herbal medicines will at least in part be regulated in the same way as conventional pharmaceuticals. ${ }^{12}$ Herbal medicines are not given regulatory categories and T\&CM providers practice in the private sector. ${ }^{12}$ However, Mothibe and Sibanda, ${ }^{38}$ write that the use of African traditional medicine by the public will 
persist and keep growing. African traditional medicine plays a role that cannot be completely substituted by conventional medicine; hence, it will remain as a part of the healthcare option available to the population as long as it is accessible. Legislation and policies are in place to facilitate the institutionalization of traditional medicine, although there is the slow progress of applications of the various laws. Mothibe and Sibanda ${ }^{38}$ write that it is pertinent that the South African Health Products Regulatory Authority (SAHPRA) has to accelerate the framework of regulation of the production of African traditional medicines for bulk sale as the market is growing rapidly, increasing the potential risks to the public. While there are notable progress and benefit in institutional research and collaboration, there is a great need to provide guidelines and regulation for collaboration at the primary health care and clinical level. Proper education of conventional health providers about African traditional medicine and the role of traditional health practitioners will facilitate understanding and trust between the two practices and benefit the health care service. The complexities that are delaying the enactment of the Traditional Health Practitioners (THP) Act should be addressed, so that the registration, training, and acceptance of THPs will be realized. This analysis here indicates that South Africa still needs much to do to meet the recommendations of Alma Ata in its health needs.

\section{Sustaining tradition, fulfilling agreements}

African countries are making an effort to integrate traditional medicine into their mainstream health systems. However, these efforts still have to yield the desired effect. Most governments still do not consider integration as a priority as far as their national health policies are concerned. A $\mathrm{WHO}^{39}$ survey on regulation of $\mathrm{TM}$ and, specifically, herbal medicines showed that $65 \%$ of Member States have laws or regulations on herbal medicines and these regulations are largely similar to those of conventional medicines. Out of these, $61 \%$ reported that they have registration systems for herbal medicines. ${ }^{37}$ There are many reasons why traditional medicine has not been fully integrated into the NHS of many African countries as recommended by WHO in the 1978 Alma Ata Conference. Firstly, it is difficult to integrate what you already have and practice.There is some reluctance in completely integrating, traditional medicine because most governments think they already have. Most African governments seem not to see the reason for this integration on the basis that they have whatit takes to manage any disease. However, they fail to appreciate the fact that traditional medicine existed before the introduction of biomedicine into the African Health System. Traditional medicine has proven its worth in handlingsome pathologies that biomedicine has failed to handle. Traditional medicinecould have been developed to compete with any other medicine but it has been neglected by policy makers, leaving it in the sole hands of the practitioners. But these practitioners lack the necessary modern resources to develop their ethnohealth technologies. They have been relying on traditional knowledge that hasbeen inherited throughout generations. Secondly, African countries are partners of global health which has implications in the global political economy of health. For this reason, the interests of global health partners' initiatives are given priority especially with the financial bene*t that goes with such actions. Global health assists African countries in meeting up their health challenges inmany domains. African governments cannot afford to lose this corporation byrelying on traditional medicine where they may need to spend more resources. Thirdly, being part of global health means reaching deals with pharmaceutical companies whose policies are at a tangent with the promotion of traditional medicine. The margin of profit-making for these pharmaceutical companies and African governments is very large. This makes it difficult to turn to the integration of traditional medicine which may still be at the rudimentary stages for most of it. Fourthly, though there have been dynamics in global health policies, from international health to health for all by the year 2000 and universal health, these changes have had little effect on changes in the land scape of the African health policies. African health policies still have strong linkages to systems left behind by colonization. The leftovers of colonization continue to influence most African governments' health policies. This still poses a challenge to the complete integration of traditional medicine into African health systems. Fifthly, there is still a conflict of interest in the complete integration of traditional medicine into NHS in Africa. Those who are benefiting from conventional medicine may see their interests threatened if integration take splace and because most of them are the decision-makers, it becomes a strong task. African governments need a strong political will to overcome thesechallenges and give importance to what belongs to them naturally, culturally, and traditionally. One can only be identified with what you have rather thanwhat you do not have.

\section{Moving beyond policy implementation of traditional medicine in Africa}

The $\mathrm{WHO}^{40}$ has tagged African medicine as having issues of efficacy, safety, quality, monitoring and control, standardization whereas this same traditional medicine has been taking care of people since time in memoriam. Itis this same traditional medicine that $\mathrm{WHO}^{5}$ says about $80 \%$ of Africansuse, yet it is not standardized. African medicine has shown through the new coronavirus (COVID-19) that it can perform well in treating patients more than conventional medicine whose vaccine trials have all failed up till now. Africansare therefore caught between the arguments and recommendations of the WHO and their indigenous knowledge of healing and healthcare. With African governments not fully convinced that they can make their medicine to be what they want, they rely on WHO and the West for counseling and provision of healthcare with Western standards. The evidence of the eleven sampled countries in Table 3 shows that the AlmaAlta recommendations and subsequent resolutions of WHO have not been followed to the latter. Of the five main resolutions of the Alma Alta, only one: Regional framework for the registration of traditional medicines in the WHO African Region has been respected by African countries. No country has be enable to develop a Model Code of Ethics for Traditional Health Practitioners. But Madagascar and to a lesser extent, Ghana and Senegal have accomplished the following: developed guidelines for the formulation, implementation, monitoring, and evaluation of a National Traditional Medicine Policy, Regional framework for the registration of traditional medicines in the WHO African Region. 
All the other eight countries or countries out of the sample are just trying to make efforts like the Malagasy, Ghanaian and Senegalese examples. As Tsekpo ${ }^{18}$ puts it, it is important to emphasize that as more and more people use traditional health care facilities, there is an urgent need for the appropriate systems of quality control in the practice as well as in the production and use of the medicines. Such systems will protect the public and also ensure that the best practices and the most useful medicines are made available in the most affordable manner. Since December 2019, a respiratory pandemic named coronavirus disease 2019(COVID-19) caused by a new coronavirus named SARS-CoV-2, has taken the world by storm. Some of its symptoms are fever, malaise, and cough which resolve in a few days in most cases; but may progress to respiratory distress and organ failure. Transmission is through droplet infection or fomites, butother modes such as airborne transmission and oro-fecal transmission are also speculated. Research is underway to develop effective vaccines and medicines for the disease. In such a scenario, different cultures have presented traditional options for treating and curing COVID-19. The Chinese, Indian and African Health Systems have been rolled out as measures for health protection during epidemics. The African health system has two major options: the COVID-19 Organic and the Kleda herbal cure (Elixir COVID). These two traditional medicines developed during the origin of the coronavirus, African peoples are employing natural drugs of herbal and animal origin for treatment and cure.

In African medicine, during an epidemic, apart from isolation and quarantine, three measures are of utmost importance, (i) purification of surroundings using certain herbal drugs as herbal portions and sprays, (ii) health promotion and immune-modulation, and (iii) use of health-protecting drugs and symptom specific drugs. Tonic drugs such as ginger, garlic, spiced and hot foods are prescribed in various forms. Scientific researches on these drugs reveal the presence of several pharmacologically active substances, which may provide new insight into the management of infections and epidemics. The dominant health system, traditional medicine in Africa, is integrating biomedicine into its system.

\section{Keeping traditional medicine in the global health plat- form}

Examining the policies that have been put in place by the countries mentioned above, we notice that there have been many shortcomings in putting them in place and also implementing them. Mbonji11 summarizes all that has been done in Cameroon and other African countries and intimates that even though much has been done on traditional medicine in Cameroon like elsewhere in Africa, the status of traditional medicine is still minor due to conventional medicine and scientific research. The status of traditional medicine is ambivalent, ambiguous, oscillating between a kind of officialization, a semilegitimacy which is not legislation, the will to associate it by imposing on it the rules of the game by allowing it to do what is allowed and what is not allowed. What is puzzling is that WHO remains committed to providing support to the Member States in the region and the promotion of the development of African traditional medicine ${ }^{41}$ Editorial of the Regional Director of WHO for Africa, Luis Gomes Sambo yet the member countries in Africa are slow in implementing WHO measures. Looking at the time that it has taken, it could be concluded that in those 42 years after Alma Ata, there has been a lot of reluctance and sluggishness in fully implementing its recommendation. From 1978 at the Alma Ata conferencetill 2020, one would have expected to see all the international recommendations implemented. Lantum and Monono ${ }^{24}$ have observed that the process has been very slow but steady. All the various countries havetheir specificities at the local level that might have prevented them from accelerating implementation. That is why all the various countries have not done so at equal levels. In the WHO global report on traditional medicine in 2019, Member States were asked whether herbal medicines are included in their National Essential Medicine List (NEML). As of 2018, 34 Member States replied in the affirmative to having herbal medicines included in their NEML of which seven are in the WHO African Region - Burkina Faso, Cameroon, the Democratic Republic of the Congo, Ghana, Madagascar, Mali, and Niger. ${ }^{12}$ Kasilo $^{42}$ has made an overview of traditional medicine in the African region where he brings out the achievements in implementing WHO traditional medicine strategies, its challenges and also proposes the way forward. After examining all of them, we observe and propose that for traditional medicine to be fully recognized and implemented in the National Health Systems (NHS) of the various WHO member countries of the African region, the various governments have to further be engaging. Firstly, vote law in their various parliaments which fully regulates the practice of traditional medicine. By doing so, the traditional healers will feel fully secured to practice their activity, quacks and charlatans will be thrown out of the profession, it will bring in the needed respect from other medical practitioners who have always under looked traditional medicine, it will finally professionalize the sector. Voting law in the various parliaments will also see the countries developing a code of ethics for traditional healers. We strongly think that some official recognition of the practice of traditional medicine in African countries is not enough to make traditional medicine have a status as compared to that of conventional medicine. Most countries have official regulation which is not equal to a parliamentary law which places traditional medicine at a prestigious position. Secondly, issues on traditional medicine should be allowed fully in the hands of the traditional healers. Traditional medicine is very holistic involving religious and spiritual components that can only be understood by its practitioners. When traditional healers take up the challenge to practice their profession in a legal context, they become more conscious of the stakes. Mbonji ${ }^{11}$ has criticized this aspect where most of the decisions taken on traditional medicine have been done so by biomedically trained personnel. As such, they have always decided on things that they do not understand. He observed that in an enlarged meeting of the Organizational Committee of traditional medicine called by the Cameroon Ministry of Public Health no. D12-61 L/MSP/SG/DOSTS/SDSSP, out of the twenty-six personnel invited, only two traditional health practitioners were amongst. We also observed that most of the decisions and recommendations of international organizations for the implementation of traditional medicine have always come from biomedical personnel. It is difficult to talk fully about what you do not master. Traditional healers must be put at the center of planning their activity and allowed to 
decide how their profession should work. After all, they have practiced their medicine that has been inherited throughout generations under the guide of their cultures. The governments should be there as a guide since it involves issues of national health.

Thirdly, most research and recommendations made as to the practice of traditional medicine have up till now been in favor of integration or collaboration with conventional medicine. It is the case with Innocent (2016) who writes that Sub Sahara African continues to suffer from diseases because the rich source of biodiversity has not been tapped. This untapped avenue has contributed minimally in solving health problems since traditional medicine has not yet been formally integrated into the existing conventional health care delivery and reason partly because few traditional medical curricula are geared to train human resources to undertake quality services and development of material medicine used in treatments in this region. Sjaak van der Geest ${ }^{43}$ disagrees with integration. He holds that governments should work for improvement in health care because that is the wish of the people. He furthers that most people know where to go when they are ill. Hence, both traditional and conventional medicine should be improved upon so that they do just what is right in bringing health care. Like Sjaak van der Geest, ${ }^{43}$ we think that more opportunities should be given for the empowering of each sector. The COVID-19 pandemic has provided evidence that rather than Africans integrating African medicine into conventional medicine, Africans are integrating conventional medicine into African Medical practice. To corroborate this, African governments have remained silent on the issue of integration. Their leaders have taken the lead in promoting African medicine where conventional medicine display weaknesses. They had prioritized conventional medicine but the context of COVID-19 has not been able to provide either a drug or vaccine, leaving their populations helpless, with little biotechnology to turn. Their last hope to save their populations has been to rely on and return to African medicine. For example, Madagascar has produced COVID-19 Organic from African herbs and proposed to their populations and those of other African countries. Cameroon has experienced the production of herbal treatment Elixir COVID by Archbishop Samuel Kleda whereby the government has linked with him to raise the hope of the population which had self-referred and embraced his treatment. From these two examples, African governments control the actions of the specialist in traditional African medicine. African leaders, who are supposed to be flag bearers of conventional medicine and assure the integration of African medicine into conventional medicine, would rather prefer treating them as parallels than as one absorbing the other.

Fourthly, traditional medicine should be given a legal status from parliament to exercise. There is the fear that the use of African medicine will drastically decline when the present generation of African medical practitioners die out because there will be very few successors of the profession. Most young people would not like to practice it because it is not protected, it lacks that prestigious position that conventional medicine enjoys and it is not very lucrative. This position is buttressed by Oyebode et $\mathrm{al}^{8}$ in a study which found out that the use of traditional medicine in six populous middle-in- come countries is much lower than has been previously reported by WHO (2002) that about $80 \%$ of Africans use traditional medicine. The country with the greatest use of traditional medicine is India where $11.7 \%$ of people reported that their most frequent source of care was traditional medicine and $19.0 \%$ of people reported at least one consultation with a traditional medical practitioner in the previous twelve months. In contrast, $<3 \%$ reported using traditional medicine as their most frequent source of care in China, Ghana, Mexico, Russia, and South Africa; and $<2 \%$ reported using traditional medicine in the last twelve months in Ghana, Mexico, Russia, and South Africa. Those who make use of traditional medicine are likely to be socio-economically disadvantaged. Awah ${ }^{44}$ had posited this view of Oyebode et al, ${ }^{8}$ explaining that the rich and educated in Africa are more likely and viable to use traditional medicine than the poor as complementary therapies because of their capacity to afford it. Awah ${ }^{45}$ observed that African traditional medicine is considered as always providing a cure for illness while biomedicine for most of the time provides the treatment. Its use is a little higher in China and India more than in Ghana and South Africa because the governments and community may give certain traditional forms of medicine considerable respect, in terms of policies and funding. This critical view needs to be considered by African governments. There is the need to uplift traditional medicine to sustain its existence for posterity given that most biomedical pharmaceutical products come from traditional medicine and traditional medicine has succeeded in most cases where conventional medicine has failed. This view is supported by the COVID-19 pandemic, where by the entire world looks up to existing traditional medical options and practices around the globe for a breakthrough even on a temporal basis. This, therefore, provides that the earlier hypothesis that traditional medicine, especially of Africa may disappear may be a false premise because it is what rekindles hope in an era of COVID-19.

Fifthly, African traditional medicine needs to be funded the same way as conventional medicine is funded. This can only be done if governments make it possible by giving a complete legal status by their parliaments. The government of Madagascar, for example, has taken the lead in funding and promotingCOVID-19 Organic medicine. It provides this medication free to citizens of Madagascar but markets it in millions of dollars to other African countries. This will encourage research into the sector. The government of Cameroon has mobilized scientists to work with Arch Bishop Kleda in researching and checking the quality of the herbal medicine offered by him. This entails, weighing in with resources that would uplift the potential of a cure for COVID-19 in a context where conventional medicine does not off er any cure. The World Health Organization is in dialogue with the government of Madagascar to enable WHO provides expertise in further researching and providing quality assurance to the Covid-19 Organic so that it may eventually be integrated in to the worldwide medical framework for curing Covid-19. If these two examples with many others in Africa are developed and sustained, it will generate the income typical of drug development and marketing and will compete in the global platform with biomedical pharmaceuticals. African traditional medicine will then become a global business and income-generating, providing the most 
needed income for African economies. The African health systems will no longer rely solely on conventional drugs for the sustenance of its medical system.

Sixthly, traditional medicine should be given its rightful place because as Asare-Damso ${ }^{46}$ writes, there is the loss of indigenous knowledge. We think that this indigenous knowledge should be protected for posterity because of its usefulness in health care, especially where conventional medicine faces challenges or has failed. Parts of African cultures and traditions are found and traced in its medicine. The role of African medicine in sustaining tradition cannot be overlooked. Furthermore, the language used to describe traditional medicine has to change. It is called traditional medicine because it has existed in a particular place over generations and it is bound and emerges from a given culture. It is traditional because it is the mainstream medicine of the people using it. What Western scientists call "conventional", "biomedicine", "modern medicine", "mainstream", "orthodox" is the traditional medicine of the people of the West. It is alternative medicine in Africa or in a culture that is not that of the West. African traditional medicine is also alternative medicine when it is being used by people in the West. There is neither a superior nor an inferior medicine. All medicines have particular roles to play in health care. If this view is considered, then the place of African traditional medicine will not be disputed but it will be harnessed to fit the context in which it exists. The inability of the governments in Africa to provide adequate and comprehensive health care to its citizens makes it incumbent on them to legally and officially give the possibility to African traditional medicine to complement the gap. This act will just boost the activities of traditional healers by making them step up health care to populations. ${ }^{47-52}$

\section{Conclusion}

African traditional medicine has undergone so many stages in its existence. It was recommended by WHO at the Alma Ata Conference of 1978 and reinforced by the 2018 Astana Declaration for WHO member countries to integrate traditional medicine into their National Health Systems. From then, it became incumbent on WHO member countries to integrate it into their National Health Systems for Primary Health Care to be accomplished. However, the argument of this paper is to argue that traditional medicine exists in parallel with conventional medicine since integration has failed. In Cameroon for instance, some traditional healthcare practitioners have changed the name over time from "traditional medicine" to "modern traditional medicine". The "modern" status of traditional medicine has been disputed by scholars. Maybe it is because it is adopting Western biomedical techniques in its production and packaging or it is a way for its practitioners to attract more customers.

Apart from Madagascar and to a lesser extent Ghana and Senegal, most African countries are still slow and reluctant in implementing the recommendations of the Alma Ata Conference for the achievement of comprehensive PHC. The worth of traditional medicine cannot only be judged from anetic position. It is time to save traditional medicine and give its desired position in national health care. Traditional medicine should be subsidized. Its practice needs to have a status voted in the various African parliaments for it to be a law where there will be freedom to practice the profession. Traditional medicine should be allowed in the hands of traditional medical practitioners so that the right decisions will be taken for the sustainability of it. It will be a failure for WHO if its recommendations and suggestions are not taken into consideration. Research needs to be reinforced to prove that traditional medicine has its place. Africa and Asia will lose one of their cultural identities if traditional medicine disappears in the future. All these recommendations here cannot work without a strong political will from global governments. By doing this, it will just mean taking back full control of what they have for it is only through it that cultural identity in health can be developed and handed to future generations. Traditional medicine is not only a cultural identity and heritage but is also a healing component that has proven its worth where other biomedicine have failed. We emphasize that instead of talking about the integration of traditional medicine, both conventional and traditional medicine have to rather operate in parallel or complementarily given that they have different operating frameworks and platforms.

\section{Ethics approval and consent to participate}

Not applicable

\section{Consent for Publication}

Not applicable

\section{Availability of data and Materials}

Data sharing not applicable to this article as no datasets were generated or analyzed during the current study

\section{Competing Interests}

The authors declare that they have no competing interests.

\section{Funding}

Not applicable

\section{Authors' Contributions}

PKA initiated the idea of the paper. PKA and ND both participated in draftingthe paper and reviewing all the contents. PKA and ND agreed on the authorship.All authors read and approved the final manuscript

\section{Acknowledgments}

Not applicable

\section{Authors' Information}

PKA is the Chair of Anthropology at the Faculty of Arts, Letters and SocialSciences, University of Yaounde I. He has previously held the position of SeniorResearch Advisor for Ipas in Chapel Hill, North Carolina, USA. A resourceful and dedicated professor with an outstanding academic background holding a Ph.D. in Medical Anthropology from the Faculty of Medical Sciences, NewcastleUniversity, Newcastle upon Tyne, UK, and a Postdoctoral Certificate in Bioethics from the Western Institutional Review Board(WIRB) Olympia and the University of Washington in Seattle, WA, USA. He is a member of the African Union Taskforce for the African Scien- 
tific Research and Innovation Council and the African Union Social and Economic Working Group. He serves as a boardmember in the WCG-WIRB in the United States of American and the CentralHospital Yaounde, Institutional Review Board, Cameroon.

DN is a holder of a Ph.D. in Medical Anthropology from the University of Yaounde I. His current research interest is in Traditional Medicine. He teachesPsychology and Counselling in the Department of Guidance and Counselling atthe Higher Technical Teacher's Training College Kumba of the University ofBuea, Cameroon. He initially trained as a teacher's trainer at the AdvancedTeachers Training College of the University of Yaounde I in Yaounde, Cameroon.He holds a teaching Postgraduate Diploma in Philosophy obtained from the Higher Teacher's Training College of the University of Yaounde 1 in Cameroon.

\section{References}

1. Mahomoodally MF. Traditional Medicine in Africa: An Appraisal of Ten Potent African Medicinal Plants. Evidence-Based Complementary and Alternative Medicine. 2013;2013:2-3.

2. Agbor MA, Naidoo S. A review of the Role of African Traditional medicine in the Management of Oral Diseases African. Journal of Traditional, Complementary and Alternative Medicine. 2016;13(2):133-142.

3. Flynn BB, Sakakibara S, Schroeder RG, et al. Empirical research methods in operations management. Journal of Operations Management. 1990;9(2):250-284.

4. Naga Vamsi Krishna Jasti, Rambabu Kodali. A literature review of empirical research methodology in lean manufacturing. International Journal ofOperations \& Production Management. 2014;34(8):1080-1122.

5. WHO. Traditional Medicine Strategy 2002-2005. Geneva. 2002.

6. WHO. Magazine of the Regional Office. African Health Monitor Jan-June 2003. Volume 5, on Traditional Medicine, Our Culture, Our Future. 2003.

7. WHO. Primary Health Care: Report of the International Conference on Primary Health Care. Alma-Ata, USSR, 6-12 September 1978, World Health Organisation, Geneva. 1978.

8. Oyebode 0 , Kandala NB, Chilton PJ, et al. Use of traditional medicine in middle-income countries. WHO-SAGE study published in Health Policy and Planning. 2016;31:984-991.

9. Lantum DN. The Pros and Cons of Traditional Medicine in Cameroon. 1978.

10. Shein K, Maehira Y. Introduction. In: WHO Global Atlas of TraditionalComplementary and Alternative Medicine. Text Volume, Kobe, Japan. 2005; xixiv.

11. Mbonji E. Sante, maladieetmédecine africaine. Plaidoyer pour l'autretradipratique. Les Presses Universitaires de Yaoundé. 2009.

12. WHO. Who Global Report on Traditional and Complementary Medicine 2019. 2019.

13. WHO. Traditional healers broaden health care in Ghana. 2019.

14. WHO. Essential Medicines and Health Products. 2008.

15. Innocent E. Trends and Challenges towards the integration of Traditional Medicine in formal Health-Care System: Historical Perspectives and Appraisal of Education Curricula in Sub-Sahara Africa. Journal of Complementary Medicine Research. 2016;5(3):1-5.

16. Fontaine M. Santeet Culture en Afrique Noire. L'Harmattan, Paris. 1995.

17. Good BJ. Medicine, Rationality, and Experience: An anthropological perspective. Cambridge University Press. 1994.

18. Tsekpo KM. Institutionalization of African traditional medicine in the health care systems in Africa. African Journal of Health Sciences. 2004;11(1-2):i-ii.

19. WHO. WHO Essential Medicines and Health Products Department. 2001.

20.WHO. Legal status of traditional medicine and complementary/ Alternative Medicine: The case of Ghana: A worldwide Review. Essential Medicines and Health Products Information Portal, A WHO resource. 2001.

21. Geiselhart K. WHO guidelines challenged in Botswana: traditional medicine between healing, politics, and witchcraft. Journal of political ecology. 2018;25(1):169-184.

22. Hillenbrand E. Improving Traditional-Conventional Medicine Collaboration: Perspectives from Cameroonian Traditional Practitioners.
Nordic Journal of African studies. 2006;15(1):1-15.

23. Fokunang CN. Traditional Medicine: Past, Present, and Future Research and Development Prospects and Integration in the National Health System of Cameroon. African Journal of Traditional, Complementary and Alternative Medicine. AJTCAM. 2011;8(3):284-295.

24. Lantum DN, Monono ME. The Republic of Cameroon, In: Bordeker G, Ong CK, Grundy C, Burford G, Shein K. WHO Global Atlas of Traditional Complementary and Alternative Medicine. 2005;13-19.

25. Ekonde D. As COVID-19 cases climb in Cameroon, a cleric claims his herbal cure works. Global Voices. 2020.

26. Kabupwe E. Ivory Coast: New Code of Ethics for traditional Medicine and Pharmacopoeia. Juri Africa. 2016.

27. Memvanga, PB, Tona GL, Mesia GK, et al. Antimalarial activity of medicinal plants from the Democratic Republic of Congo: A review. Journal of Ethnopharmacology. 2015;169:76-98.

28. WHO. WHO Traditional medicine Strategy: 2014-2023. Essential medicines and health products. 2013.

29. Brazier Y. What was ancient Egyptian Medicine Like? Medical News Today. 2018.

30. Nahla SA, Shahat AAA, El Missiry MM, et al. Egyptian Herbal Drug Industry: Challenges and Future Prospects. Research Journal of Medicinal Plants. 2011;5:136-144.

31. Harrington J. Kenya: Traditional Medicine and the law. African Research Institute Committee on Development and Intellectual Property (CDIP) $13^{\text {th }}$ session, Geneva, May 19-23 2014, Country study on innovation, intellectual property and the informal economy: traditional Herbal Medicine in Ghana. 2016.

32. Pierlovisi C, Pourchez L. Traditional Medicine in Madagascar - Current Situation and the institutional Context of promotion. Health, Culture, and Society. 2014;14-27.

33. Ekeanyanwu CR. Traditional Medicine in Nigeria: Current Status and the Future. Research Journal of Pharmacology: Medwell Journals. 2011;5(6):90-94.

34. Iwasa M, Ohno Y. Traditional Healers' Practices on Traditional Medicine in Rural Senegal Villages. Nursing Journal of Mukogawa Women's University. 2017;02:93-100.

35. Bobb S. Efforts in Senegal to Join Traditional and Conventional Medicine. Voice of America. 2009.

36. Haque N. Senegal Split over Legalising Traditional Medicine. Aljazeera. 2018

37. Ngcobo M, Nkala B, Moodley I, et al. Recommendations for the Development and Regulatory Guidelines for the Registration of Traditional Medicine in South Africa. AJTCAM. 2012;9(1):59-66.

38. Mothibe ME, Sibanda M. African Traditional Medicine: South African perspective. Traditional and Complementary Medicine. 2019:1-27.

39. WHO. National Policy on Traditional Medicine and the Regulation of Herbal Medicines: WHO. Report of a WHO Global Survey, WHO, Geneva. 2005.

40. WHO. Final Report on Regional Meeting on the Institutionalization of Traditional Medicine. WHO, Health Systems, Ouidah, Republic of Benin, Regional Office for Africa, Brazzaville. 2004.

41.WHO. African Traditional Medicine Day. The African Health Monitor. 2010

42. Kasilo OMJ, Trapsida JM, Mwikisa CN, et al. An Overview of the Traditional Medicine Situation in the African Region. In: The African Health Monitor, WHO. 2010:7-15.

43. Sjaak van der Geest. Is there a role for Traditional Medicine in basic Health Services in Africa? A plea for a community perspective. Tropical Medicine andInternational Health, Blackwell Science Ltd. 1997;2(9):903-911.

44. Awah PK. Treating Diabetes in Cameroon: A comparative study in medical anthropology. School of Population and Health Sciences, Faculty of Medical Sciences. 2006.

45. Awah PK, Phillimore PR. Diabetes, Medicine and Modernity in Cameroon. Africa. 2011;78(4):475-495.

46. Asare-Damso S. The traditional Approach to the Management of Diseases in Ghana. Legion. Journal of Sociology. 2005;2(2):69-80.

47. Asonganyi T. Relationship between Conventional and Traditional Medicine in Cameroon. Health Sciences and Disease, Health Sciences and Disease. The Journal of Medicine and Health Science. 2011;12(2):1-2.

48. Bordeker G, Ong CK, Grundy C, et al. WHO Global Atlas of Traditional Complementary and Alternative Medicine. Text Volume. Kobe, Japan. 2005. 
49. Kleinman A. Patients and Healers in the Context of Culture. Berkeley, University of California Press. 1980.

50. Payyappallimana U. Role of Traditional Medicine in Primary Health Care: An overview of perspectives and challenges. United Nations University. 2010.

51. Traore F, Bamba KD, Kof F, et al. Traditional Medicine followed at the Heart Institute of Abidjan. Scientific Research: An Academic Publisher. 2017;07(09):292-298.
52. WHO. Rapport, Comité Régionald' Experts de L'OMS sur la Médecine Traditionnelle. WHO, Harare, Zimbabwe. 19-23 Novembre 2001, Rapport Final de la Première Réunion, WHO, Bureau Régionale de L'Afrique, Brazzaville. 2004. 